\title{
UPAYA MENINGKATKAN KEMAMPUAN PEDAGOGIK GURU MELALUI PELATIHAN PEMBELAJARAN TEMATIK SAINS MENGGUNAKAN INQUIRY LEARNING PROCESS DAN SCIENCE ACTIVITY BASED DAILY LIFE
}

\section{IMPROVING THE TEACHER PEDAGOGICAL ABILITIES THROUGH THEMATIC SCIENCE LEARNING TRAINING USING INQUIRY LEARNING PROCESS AND SCIENCE ACTIVITYBASED DAILY LIFE}

\author{
${ }^{1)}$ Subuh Anggoro, ${ }^{2}$ Sri Harmianto, ${ }^{3)}$ Pratik Dwi Yuwono \\ ${ }^{1,2,3)}$ Program StudiPendidikan Guru SD, FakultasKeguruan dan Ilmu Pendidikan \\ UniversitasMuhammadiyahPurwokerto \\ Jl. Raya DukuhWaluh PO BOX 202 Purwokerto 53182 \\ Telpon: (0281)636751 ext : 130 Fax (0281)637239 \\ email: subuhanggoro@ump.ac.id
}

\begin{abstract}
ABSTRAK
Kegiatan ini bertujuan untuk meningkatkan kemampuan pedagogik guru melalui pembelajaran tematik sains menggunakan inquiry learning process dan science activity based daily life.Metode kegiatan yang dilakukan adalah (1) memberikan pemahaman tentang pentingnya pembelajaran tematik sains menggunakan inquiry learning process dan science activity based daily life; (2)melakukan simulasi kegiatan pembelajaran tematik menggunakan menggunakan inquiry learning process dan science activity based daily life; dan (3) melakukan monitoring dan evaluasi. Kegiatan tersebut diikuti oleh 48 guru dan 9 kepala SD/MI Muhammadiyah se Kabupaten Banyumas. Sebagian besar peserta telah memahami dan tiga peserta bahkan telah mempraktekkan pembelajaran tematik sains menggunakan inquiry learning process dan science activity based daily life.
\end{abstract}

Kata kunci : Tematik Sains, Inquiry Learning Process, Science Activity Based Daily Life

\section{ABSTRACT}

The objectives of this activity is to improve teacherspedagogic abities through the science thematic learning using inquiry learning process and science activity based daily life training. Methods of activities undertaken are (1) providing the understanding of the importance of science thematic learning using inquiry learning process and science activity based daily life; (2) simulating thematic learning activities using inquiry learning process and science activity based daily life; and (3) monitoring and evaluation. The event was attended by 48 teachers and 9 heads of Primary School / MI Muhammadiyah in Banyumas Regency. Most participants have understood, besides three participants have even practiced science thematic learning using inquiry learning process and science activity based daily life.

Keywords: Science Thematic Learning Traing, Inquiry Learning Process, Science Activity Based Daily Life

Submited : 18 September $2017 \quad$ Revision :9 Desember $2017 \quad$ Accepted : 5 Maret 2018

\section{PENDAHULUAN}

Pembelajaran IPA atau sains merupakan salah satu mata pelajaran yang masih dianggap sulit oleh siswa sekolah dasar. Hal ini bertolakbelakang dengan tujuan dari pembelajaran IPA. IPA berupaya membangkitkan minat manusia agar mau meningkatkan kecerdasan dan pemahamannya tentang alam seisinya yang penuh dengan rahasia yang tak habis- 
Subuh Anggoro, Sri Harmianto, Pratik Dwi Yuwono Upaya Meningkatkan Kemampuan Pedagogik Guru melalui Pelatihan Pembelajaran Tematik Sains menggunakan Inquiry Learning Process dan Science Activity Based Daily Life

habisnya. Pembelajaran IPA sejak dini diharapkan siswa memiliki kemampuan untuk menanya (ask the question), mengumpulkan informasi (collect information), mampu mengorganisasi dan menguji coba ide yang dimilik i organize and test ideas), dapat mengatasi masalah dan mengaplikasikan pengetahuan yang diperoleh dalam kehidupan sehari-hari (to problem solve and apply what we learn) (lets talk science, 2014). Dengan demikian diharapkan akan terbangun rasa percaya diri yang tinggi (building confidence), kemampuan komunikasi yang baik (developing communication skills) dan memiliki kepekaan terhadap lingkungan tempat tinggalnya (making sense of the world around). Kemampuan-kemampuan tersebut akan dapat diperoleh apabila siswa merasa bahwa IPA berlangsung secara inkuiri dan kontektual dengan kehidupan nyata.

Berdasarkan wawancara dengan Bapak Rohman, S.Pt, Kepala MI Muhammadiyah Cipete, Ibu Wainah, S.Pd.I, Kepala MI Muhammadiyah Pasirmuncang dan Bapak Samsuri, S.Pd.I, Ketua K3S SD/MI Muhammadiyah dan observasi dari 2 MI Muhammadiyah di Kabupaten Banyumas, permasalahan yang terjadi adalah karena dalam proses pembelajaran, sebagian besar guru berpendapat metode ceramah adalah yang paling efektif menginga tbanyaknya materi yang harus diberikan. Padahal agar proses pembelajaran IPA menyenangkan membutuhkan inquiry learning process dan hands-on activities based on daily life.

Penggunaan metode dan media pembelajaran tepat, menarik dan menyenangkan membuat siswa cenderung semakin giat belajar IPA. Hal ini sesuai dengan hasil penelitian yang dilakukan oleh Kendaryadi (2010), Nababan (2010), Utami (2010), Sumaryanto (2010), Marganingsih (2010) dan Muqoyyanah (2010) yang menunjukkan bahwa penggunaan alat peraga diketahui dapat meningkatkan sikap siswa dalam mempelajari IPA di SD dan SMP.

Melalui kegiatan hands-on exercises dan role playing, siswa kelas mendapatkan peningkatan aspek mengingat, memahami, mengaplikasikan yang lebih tinggi (Anggoro, 2014). Hasil penelitian Yakoob dkk (2011) menyebutkan bahwa 99\% siswa senang belajar Sains melalui hands-on activity. Disamping itu 99,3\% siswa menyatakan bahwa mereka ingin belajar Sains lebih banyak di masa depan. Sudarisman (2011) menyatakan bahwa melalui hands-on activities base on daily life membuat siswa merasakan belajar Sains lebih bervariasi, menyenangkan dan meaningful.

Berdasarkan hasil penelitian Anggoro dan Husin (2008), Anggoro dan Iswasta (2009) dan Anggoro dan Badarudin (2010) menunjukkan bahwa pembelajaran menggunakan metode ceramah atau diskusi tingkatk eberhasillannya lebih rendah dibandingkan apabila menggunakan pendukung alat peraga. Anggoro (2014) menyatakan bahwa siswa lebih baik dalam memahami dan mengingat konsep IPA ketika minat siswa tinggi atau mereka mendapatkan jawaban secara mandiri melalui kegiatan inkuiri.

Untuk mengatasi kondisi seperti itu dibutuhkan guru yang kreatif dalam mengembangkan proses pembelajaran, khususnya di bidang IPA. Hal itu sangat diperlukan karena kemampuan mengembangkan proses pembelajaran merupakan cerminan guru yang 
Subuh Anggoro, Sri Harmianto, Pratik Dwi Yuwono Upaya Meningkatkan Kemampuan Pedagogik Guru melalui Pelatihan Pembelajaran Tematik Sains menggunakan Inquiry Learning Process dan Science Activity Based Daily Life

profesional. Dengan pemahaman dan pengalaman melaksanakan inquiry learning process dan hands-on activities based on daily life. khususnya di bidang mata pelajaran IPA, diharapkan pemahaman peserta didik dapat meningkat yang bermuara pada meningkatnya prestasi belajarnya.

\section{METODE}

Kelompok sasaran penerapan ipteks adalah guru SD/MI Muhammadiyah yang tergabung dalam K3S SD/MI Muhammadiyah Kabupaten Banyumas dengan jumlah 38 sekolah dan 240 guru baik guru PNS, yayasan maupun honorer. Sehingga penerapanhasillpteks yang telahdikembangkan di PGSD UMP ini diharapkandapatditerapkanataudisosialisasi kankepada SD/MI Muhammadiyah yang merupakan ujung tombak dari pendidikan dasar.

Metode kegiatan yang dilaksanakan setelah melakukan diskusi dengan Kepala MIM Cipete adalah (1) pelatihan pembelajaran tematik sains menggunakan konsep inquiry learning process dan science activity based daily life.dan (2) membuat video dan buku panduan Pembelajaranm enggunakan konsep Inquiri Learning Process dan Science Activity Based Daily Life.

\section{HASIL DAN PEMBAHASAN}

Sasaran kegiatan ini adalah guru
SD/MI Muhammadiyah Kabupaten
Banyumas terutama yang berdekatan
dengan SDIT Muhammadiyah Cipete
Kecamatan Cilongok Kabupaten
Banyumas. Peserta pelatihan adalah 9
Kepala dan 48 guruSD/MI
Muhammadiyah. Sedangkan waktu

pelaksanaan pelatihan adalah $5-6$ September 2017. Kemudian dilanjutkan dengan monitoring di SDIT Cipete.

Peserta pelatihan ternyata antusias selama mengikuti pelatihan. Materi pelatihan dirasakan sangat dibutuhkan oleh peserta karena membahas tentang bagaimana pembelajaran tematik baik dari sisi filosofi, teori dan implementasinya. Disamping itu disampaikan tentang bagaimana pembelajaran berbasis otak (brain based learning).

Peserta pelatihan juga terlibat aktif dalam proses pelatihan. Mereka antusias melakukan praktek pembelajaran tematik sains menggunakan media puzzle. Secara aktif mereka melakukan beberapa tahapan dari inquiry process seperti bertanya, mengamati, sampai dengan mengkomunikasikan hasil yang mereka peroleh. Disamping itu, kerjasama antar anggota tim dapat berlangsung dengan lancar karena mereka merasa bertanggungjawab untuk mencapai hasil yang direncanakan.

Pelatihan pembelajaran tematik sains yang dilakukan bersesuaian dengan ciri-ciri joyful learning yang dikemukakan oleh Corbeil (1999), Meier (2000) danWolk (2008). Menurut Corbeil (1999) cirri joyful antara lain: adanya lingkungan yang rileks, menyenangkan, tidak membuat tegang (stress), aman, menarik, dan tidak membuat peserta ragu mengaplikasikan sesuatu meskipun keliru untuk mencapai keberhasilan tinggi.

Ciri lainnya adalah ketersediaan materi pelajaran dan metode yang relevan, terlibatnya semua indera dan aktivitas otak kiri dan kanan, situasi belajar yang menantang (challenging) bagi peserta untuk mengeksplorasi materi yang sedang dipelajari, sertasituasi belajar emosional yang positif ketika peserta belajar bersama, 
Subuh Anggoro, Sri Harmianto, Pratik Dwi Yuwono

Upaya Meningkatkan Kemampuan Pedagogik Guru melalui Pelatihan Pembelajaran Tematik Sains menggunakan Inquiry Learning Process dan Science Activity Based Daily Life

membuat suasana belajar lebih menyenangkan (Anggoro et al., 2017).

Pada kesempatan monitoring dan kunjungan dilakukan pembuatan video pembelajaran tematik sains menggunakan konsep inquiri learning processdan science activity based daily life. Tema yang diajarkan adalah Cita-citaku dengan tiga sub tema yaitu (1) Dokter dan Stetoskop; (2) Musisi dan Alat Musik; dan (3) Erosi dan akibatnya. Guru mengajar adalah Irma Nurlaeli, S.Pd (Dokter dan Stetoskop); Ratih Widyaningrum, S.Pd (Musisi dan Alat Musik); dan Sri Mulyati, S.Pd (Erosi dan Akibatnya).

Media pembelajaran yang digunakan adalah barang yang mudah didapat atau bahkan barang bekas, antara lain selang, T hub, corong minyak tanah, balon dan selotip untuk sub tema Dokter dan Stetoskop. Kemudian botol kaca bekas, ember, gelas dan sendok untuk sub tema Musisi dan Alat Musik. Sedangkan untuk sub tema Erosi dan Akibatnya menggunakan botol plastik bekas, media tanah, dan ember. Adapun rencana pembelajaran yang digunakan merupakan adaptasi dari buku kurikulum 2013 tema Cita-citaku. Sedangkan percobaan yang dilakukan menyesuaikan dengan hands-on activities based on daily life.

Proses pembelajaran yang dilakukan oleh ketiga guru SDIT Cipete selaras dengan yang dikemukakan oleh Meier (2000). Siswa merasakan suasana pembelajaran yang membangkitkan minat belajar, rileks, dan menarik sehingga membuat siswa semangat dan berkonsentrasi tinggi selama pembelajaran. Adanya keterlibatan penuh dalam pembelajaran ditunjukkan dengan kemauan untuk menyediakan sendiri peralatan dan pembagian tugas dalam kelompok secara mandiri dengan gembira.
Berdasarkan hasil penelitian Anggoro (2014) dan Anggoro et al.(2017) menunjukkan bahwa siswa mendapatkan pengalaman kognitif yang positip terhadap pembelajaran melalui materi pelajaran yang bermanfaat, metode dan media pembelajaran yang tepat, serta guru yang baik. Apabila hal tersebut didukung pengalaman afektif melalui materi pelajaran yang menarik, metode dan media pembelajaran yang menarik dan menyenangkan serta antusias dan menyenangkan, membuat siswa memiliki keinginan atau kecenderungan positip untuk mempelajari Sains (pengalaman konatif).

Weiet al. (2011) mengungkapkan bahwa siswa lebih mudah mengingat dan memahami dengan baik apa yang mereka pelajari apabila hal itu menarik atau mengandung bagian yang membuat mereka haru smenemukan sendiri jawabannya. Disamping itus iswa lebih mudah mengingat dan memahami sebuah konsep dengan cara bermain atau melakukan kegiatan (Jadal, 2012a dan Jadal, 2012b). Ketika ketertarikan siswa tinggi, stress dan kecemasan akan menurun, sehingga siswa lebih dapat menerima kesalahan mereka dan mau mencoba kembali. Dengan demikian karena focus mereka meningkat, siswa akan lebih mudah memahami materi yang diberikan guru (Willis, 2007)

Guru memiliki hubungan yang sangat erat dengan siswa. Siswa senang berbagi suka dan duka dengan guru. Siswa sangat mempercayai guru dan tidak takut mengekspresikan harapan dan keinginan mereka. Di Dirgantara School India, guru memperhatikan kemampuan siswa sejak awal dan memberikan tugas berdasar kemampuan dan potensi yang dimiliki siswa. Bagi guru berlaku anggapan bahwa 'We never beat any child as we believe love, attention and care is the need of the 
Subuh Anggoro, Sri Harmianto, Pratik Dwi Yuwono Upaya Meningkatkan Kemampuan Pedagogik Guru melalui Pelatihan Pembelajaran Tematik Sains menggunakan Inquiry Learning Process dan Science Activity Based Daily Life

hour for the holistic development of the child' (Chopra dan Chabra, 2013).

Ketika pelajaran bersifat membosankan, tidak relevan dengan kehidupan mereka, atau membingungkan akan menimbulkan kondisi stres bagi siswa. Dalam kondisi seperti ini, informasi tidak dapat melewati amigdala untuk menuju tingkat berpikir yang lebih tinggi serta pusat memori otak. Apabila kondisi ini berlangsung lama, maka bisa membawa kepada kerusakan dan kehilangan hubungan sinaps-sinaps dan dendritdendrit penting pada hippocampus. Informasi baru tidak bisa mencapai wilayah otak yang menjadi tempat pemrosesannya, yang berhubungan dengan dengan pengetahuan sebelumnya, serta penyimpanan untuk pemanggilan pada waktu berikutnya (Kohn, 2004; Willis, 2011).

\section{SIMPULAN}

Hasil pelatihan pembelajaran tematik sains Menggunakan Inquiry Learning Process Dan Science Activity Based Daily Life Bagi Guru SD/MI Muhammadiyah adalah (1) Guru mendapat pengetahuan tentang pemanfaatan Games Cerdas Kreatif dan media inovatif ekonomis dalam pembelajaran tematik ; (2) Siswa mendapat keuntungan berupa pemahaman konsep yang lebih menarik dengan cara yang lebih menyenangkan karena mereka yang lebih aktif baik secara fisik maupun mental dalam proses pembelajaran.

\section{DAFTAR PUSTAKA}

Anggoro, S dan Arief Husin, (2008). Upaya Peningkatan Pemahaman Mahasiswa dalam Mata Kuliah Fisiologi Tumbuhan melalui Pembelajaran CBSA Model Pengajaran Discovery. Laporan
Hibah Pengajaran P3AI UMP

Tahun 2009. UMP. Purwokerto

Anggoro, S. dan Karma I. Eka, (2009). Dry Lab Model (Upaya Pengembangan Perangkat Praktikum Pembelajaran BIOLOGI SD). Laporan Hibah Pengajaran PHK S 1 PGSD Tahun 2009. UMP. Purwokerto. tidak dipublikasikan

Anggoro,S. (2014). Analisis Perbandingan Sikap Belajar dan Penguasaan Konsep IPA menggunakan Strategi Joyful Learning di Kelas IV SD Kota Bandung.Thesis UniversitasPendidikan Indonesia. Bandung. tidak dipublikasikan

Anggoro.S. dan Badarudin. (2010). Meningkatkan Pemahaman Mahasiswa dalam Mata Kuliah Konsep Dasar IPA menggunakan Model Pembelajaran CBSA denganP endekatan Discovery. Jurnal Khazanah Pendidikan, 3 (2):

Anggoro, S. dan Badarudin. (2015). Media Pembelajaran Bumi dan Ruang Angkasa berbasis Multimedia. Jurnal Dinamika Pendidikan Dasar, (VII), 1,

Anggoro, S., W. Sopandi dan M. Sholehuddin. (2017). Influence of Joyful Learning on Elementary School Students'Attitudes Toward Science. Journal of Physics Conference Series, 812 (2017) 012001, pp 1-7 doi:10.1088/17426596/812/1/012001

Chopra, V.\& S.Chabra. (2013). Digantar In India: a case study for joyful learning.Journal of Unschooling and Alternative Learning 7 (13).hlm. 28-44. [Online] tersedia di: 
Subuh Anggoro, Sri Harmianto, Pratik Dwi Yuwono

Upaya Meningkatkan Kemampuan Pedagogik Guru melalui Pelatihan Pembelajaran Tematik Sains menggunakan Inquiry Learning Process dan Science Activity Based Daily Life

http://jual.nipissingu.ca/Archives /v7113/v7132.pdf

Corbeil, P. (1999). Learning from the

Children: Practical and

Theoretical Reflections on

Playing and Learning.

Simulation and Gaming 30(2).

hlm. 163-180. [Online] tersedia

di: :http://sag.sagepub.com/

content/30/2/163

Hart, C., (2000). What is the purpose of this experiment? Or can students learn something from doing experiments? J Res Sci Teach, 37.hlm. 655-675. [Online] tersedia di:

http://www.mah.se/pages/28044/ artikel.pdf

Jadal M.M., (2012a). Use of activity based joyful learning approach in teaching environmental science subject at primary level. Indian Streams Research Journal, 2(7). hlm. 1-5 . [Online]di:

http://www.isrj.net/UploadedDat a/1226.pdf

Jadal, M.M., (2012b). Increasing the achievement of students by using the activity based joyful learning approach. Journal of Arts and Culture, 3(2). hlm. 110114.[Online] tersedia di:http://www.bioinfo.in/content s.php?id=53.

Kendaryadi, B. (2010). Hubungan antara penggunaan alat peraga ipa dengan hasil belajar IPA kelas V a SD Katolik Santo Paulus SunterJakarta-Utara. [Online] tersedia di http://garuda.kemdiknas.go.id/jur nal/detil/id /0:620587/q/alat

Mengembangkan Ketrampilan Proses Sains Dan Membangun Karakter
$\% 20$ peraga

\%20ipa/offset/0/limit/15

lets talk science. (2014). Why is science literacy so important? [Online] tersedia di: http://www.letstalkscience.ca/ab out-us/why-science

Marganingsih, A. (2010). Penerapan Guided Note Talking dengan Bantuan Alat Peraga Gambar Untuk Meningkatkan Kualitas Pembelajaran Biologi Siswa Kelas VII C SMP Negeri 2 Banyudono Tahun Ajaran 2008/2009. [Online] tersedia di:http://garuda.kemdiknas.go.id/ jurnal/detil/id/0:167655/q/marga ningsih\%20atik/offset/0/limit/15

Meier, D. (2000).The Accelerated Learning Handbook. A Creative Guide to Designing and Delivering Faster, More Effective Training Programs. New York: McGraw Hill. 145 hlm.[Online] tersedia di: http://www.psikiyatr.com/other/l earninghandbook.pdf

Nababan, R. M. (2010). Meningkatkan hasil belajar IPA dengan menggunaan alat peraga pada topik sistem pencernaan manusia pada siswa Kelas V SD BUNDA MULIA Jakarta [Online] tersedia di:

http://garuda.kemdiknas.go.id/jur naldetil/id/0:617099/q/alat\%20p eraga\%20ipa/offset/0/limit/15

Sudarisman, S. (2011).Pembelajaran Sains Pada Pendidikan Anak Usia Dini Melalui Hands On Activities Based On Daily Life Untuk

Anak. Prosiding Seminar Internasional ke-3 dan Workshop 
Subuh Anggoro, Sri Harmianto, Pratik Dwi Yuwono

Upaya Meningkatkan Kemampuan Pedagogik Guru melalui Pelatihan Pembelajaran Tematik Sains menggunakan Inquiry Learning Process dan Science Activity Based Daily Life

Pedagogik Praktis yang Berkualitas (p. 320-335. Bandung: UPI Bandung.

Sumaryanto, (2010). Penggunaan Media Untuk Meningkatkan Hasil Belajar IPA Tema Energi Dan Peranannya pada Siswa Kelas III SD Charitas Jakarta. [Online] tersedia di http://garuda.kemdiknas.go.id/jur nal/detil/id/0:618801/q/pengguna an $\% 20$ media\% 20untuk\%20meningkatkan $\% 20 \mathrm{~h}$ asil\%20belajar\%20ipa\%20tema $\% 20$ energi/offset/0/limit/15

Utami, S. D. (2010). Meningkatkan Hasil Belajar Biologi Siswa Melalui Penerapan Guided Note Taking Dengan Bantuan Alat Peraga Pada Siswa Kelas VIIc SMP Negeri 24 Surakarta Tahun
Ajaran 2008/2009. [Online] tersedia di http://garuda.kemdiknas.go.id/jur nal/detil/id/0:160304/q/guided\% 20note\%20taking/offset/0/limit/1 $\underline{5}$

Wolk, S. (2008). Joy in School. Educational Leadership, 66(1).p 8-15. [Online] tersedia di: http://www.ascd.org/publications /educationalleadership/sept08/vol66/num01/J oy-in-School.aspx

Yakoob, N., M. Ali, S. Salehdan M.A. Samsudin. (2011). Sains informal sebagai pemikat subjek sains.. Prosiding Seminar Internasional ke-3 dan Workshop Pedagogik Praktis yang Berkualitas. (p 345-356). Bandung: UPI Bandung 